\title{
Stress and the Desire to Study of Students in Higher Education Institutions During COVID-19 Pandemic.
}

\author{
Rejla Bozdo, \\ Faculty of Economy, University of Tirana, \\ Elbasani Str., 1005 \\ Albania
}

Received: June 16, 2021. Revised: July 19, 2021. Accepted: July 23, 2021. Published: July 27, 2021.

\begin{abstract}
During 2020, the world faced the unusual situation of COVID-19 infections outbreak and at the same time people and governments faced the changes in lifestyle that was forced by the measures taken to manage the crises. Measures as social and physical distancing, in addition to self-quarantine, have been imposed by governments worldwide. Education sector was affected by the measures. Students were out of school worldwide. Education moved to the online and remote learning, posing new challenges for students and teachers. The new lifestyle caused stress for many people al around the world, students included.
\end{abstract}

This research aims to investigate students' behavior during 2020 on the level of stress, desire to study, laziness and concentration and gender differences. Through a cross-sectional online survey among 254 students of higher education institutions in Albania, was found out that stress levels of students in higher education institutions were higher among female students compared to male students. The research shows that stress has negative correlation to the desire to study and concentration and positive correlation to laziness, while the desire to study has negative correlation to laziness and positive correlation to concentration. Through linear regression analysis, this study provides insights on the factors that have influenced students' feelings during pandemic and what can be done for improvement.

Keywords - covid-19, students, stress, desire to study

\section{INTRODUCTION}

Covid-19 caused the biggest disruption ever to education in history and the largest challenge ever. Isolation a quarantine also had effects on students' lives. Students cut off physical contact with colleagues and teachers, reduced mobility, got sick in their homes, faced financial problems, etc. According to World Bank, in April 2020, during the peak of school closings, $94 \%$ of students were out of school worldwide. [1] A report released on April 2021 from bestcolleges.com on a survey done in late February and early March among more than 700 students shows that $95 \%$ of undergraduate students, have had negative mental health symptoms as a result of circumstances caused by COVID-19 and $97 \%$ have experienced some negative outcome at home as a result of the pandemic. $99.6 \%$ of respondents in the research presented in this paper had stress levels $>1$, in a scale from 1 to 10 . The same research shows that the 
respondents faced social isolation, loneliness increased anxiety (45\%) and struggles with laziness, focus and routine $(44 \%)$, half of respondents said that they have struggled to finish homework showing that academic work has also suffered. [2] There are data that show students stress were experiencing high stress levels even prior to COVID-19, but the physical distancing measures, campus closers, quick pivot to remote learning, uncertainty about their future, etc., create a cumulative toll that may have affected event more students' stress level and mental health. A survey conducted in Canada during 2019, consisting of 55,284 respondents shows that over $51.6 \%$ of students felts so depressed that it was difficult to function any time during last 12 months and $68.9 \%$ felt overwhelming anxiety any time during last 12 months. [3] Preliminary data of another research conducted in Canada on the effects of COVID-19, suggests that "COVID-19, may be affecting students who identify as male and female differently. More female students indicate that the COVID-19 pandemic has been extremely disruptive to their stress and mental health, and that it has significantly disrupted their academic studies. In addition, a greater proportion of female students compared to males report that social isolation has been difficult and very difficult." [4] A survey made in Albania, during $22^{\text {nd }}$ March $-4^{\text {th }}$ April 2020, on the impact of anxiety on perceptions during the lockdown of COVID-19 shows also that "there are group differences for the Anxiety variable suggesting that the male and female levels of experiencing anxiety during the quarantine are affected by gender", indicating that female anxiety levels were higher than male. [5]

The need to use new technologies (like personal computers, tablets, and smartphones) was not always possible due to "digital divide" and economic issues. In each country, as the previous and new socioeconomic levels of families range from high to very low, the quality of housing solutions, the size of houses and spaces available for each person in the house change a lot from one family to another. [6] Also, in developing countries, these facilities may not be available and students' education may be disturbed. It was also found that further developments in E-learning and its association with students' emotions are needed, especially in developing countries. [7] An online survey completed by students studying a healthcare-oriented degree in a university in Jordan students were found to be significantly affected mentally during pandemic, with many showing borderline abnormal anxiety (22.4\%) and depression (33.8) symptoms. The learning process was also found to be negatively affected, as reported by $54 \%$ of the students. [8]

\section{METODOLOGY}

A descriptive cross-sectional online survey was conducted in Albania among 297 respondents, during 30 th April 2021 to $15^{\text {th }}$ May 2021, from which the 254 declared as students at the moment of filling the online survey, are part of the results in this research paper. The aim of this survey is to investigate on time spent on study and the desire to study during pandemic and factors that might have affected the variables of time and desire.

\section{Research context}

Since the $9^{\text {th }}$ of March 2020, the Albanian government started issuing the anti-COVID-19 measures that were toughened in the following weeks of March and April. The education institutions were closed and other public and private services were limited. During this period, higher education institutions in Albania applied remote learning, mainly. Since October 2020, the academic year has been conducted fully online.

\section{Participants}

In this survey there are 254 students of higher education institutions who responded to the questions analyzed in this research paper. $87.4 \%$ are female and $12.6 \%$ are male. Mean age of participants is 22.12 years old $(\mathrm{SD}=2.765)$.

\section{Research questions}

This paper aims to give answers to the following research questions regarding feelings of students of higher education institutions, during 2020:

1- What is the stress level of students?

2- Is there any difference between genders (male and female) in the stress levels of students?

3- What is the desire to study level of students?

4- Is there any difference between genders in "Desire to study"?

5- What is the laziness level of students?

6- Is there any difference between genders in the level of "Laziness" felt during 2020?

7- What is the level of concentration among students compared to before the pandemic?

8 - Is there any difference between genders in the level of "Concentration" felt during 2020?

9- What is the relation between Stress and the Desire to Study?

10- What is the relation between Stress and Concentration?

11- What is the relation between Stress and Laziness?

12- What is the relation between Desire to Study and Concentration? 


\section{Instruments}

In this online survey, people were asked:

- W rate their level of Stress in a scale of 1 to 10 where 1 is not at all and 10 is extremely much (Question: If you would rate the level of stress felt by you during 2020 , what is the level of stress by you?)

- $\quad$ rate their level of Desire to Study in a scale from 1 to 10 where 1 is not at all and 10 is extremely much (Question: If you would rate the level of Desire to Study felt by you during 2020, what is the level of Desire to Study by you?)

- W rate their level of Laziness in a scale from 1 to 10 where 1 is not at all and 10 is extremely much (Question: If you would rate the level of Laziness felt by you during 2020, what is the level of Laziness by you?)

- W rate their level of Concentration in a scale from 1 to 10 where 1 is not at all and 10 is extremely much (Question: If you would rate the level of Concentration felt by you during 2020, what is the level of Concentration by you?)

Data Analysis

The data was analyzed through SPSS 22.0 using descriptive statistics, correlation, independent t-test and linear regression. Descriptive statistics give a clear picture of the behavior in general; statistical tests explain the relations between variables of stress, desire to study, laziness, concentration and the differences between genders for these variables.

\section{Research Limitations}

The results of this study are limited to the sample and represent sample characteristics but they cannot be generalized due to the sample size.

\section{RESEARCH RESULTS AND FINDINGS}

Descriptive statistics for 254 students of higher education institutions participating this survey, are:

(Table 1.: Descriptive statistics of Age and Gender.)

Descriptive Statistics
\begin{tabular}{|l|l|l|l|l|l|}
\hline & N & Minimum & Maximum & Mean & Std. Deviation \\
\hline Age & 221 & 18 & 40 & 22.12 & 2.765 \\
G ender & 254 & 1 & 2 & 1.13 & 332 \\
Valid N (listwise) & 221 & & & & \\
\hline
\end{tabular}

There are four variables taken in consideration in this study.

Stress - represents the stress level of students during 2020 in a scale from 1 to 10 ( 1 is not at all, 10 extremely much)

Desire to study - represents the desire to study of students during 2020 in a scale from 1 to 10 ( 1 is not at all, 10 extremely much)

Laziness - represents the level of feeling lazy of students during 2020 in a scale from 1 to 10 ( 1 is not at all, 10 extremely much)

Concentration - represents the level of concentration of students while working or studying during 2020 in a scale from 1 to 10 ( 1 is not at all, 10 extremely much)

Gender - Male/Female

(Table 2.: Group statistics of variables: stress, desire to study, laziness and concentration.)

\begin{tabular}{|c|c|c|c|c|c|}
\hline & Gender & $\sqrt{\mathrm{N}}$ & Mean & Std Deviation & Std ErrorMean \\
\hline \multirow[t]{2}{*}{ Stress } & Female & 222 & 7.77 & 1.987 & .133 \\
\hline & Male & 32 & 6.97 & 2.024 & 358 \\
\hline \multirow[t]{2}{*}{ Desire_study } & Female & 221 & 5.71 & 2.673 & .180 \\
\hline & Male & 32 & 5.66 & 2.585 & 457 \\
\hline Laziness & Female & 221 & 7.61 & 2.233 & .150 \\
\hline & Male & 32 & 7.38 & 2.225 & .393 \\
\hline \multirow[t]{2}{*}{ Concentration } & Female & 221 & 4.81 & 2.212 & .149 \\
\hline & Male & 32 & 5.28 & 2.159 & .382 \\
\hline
\end{tabular}

Descriptive statistics show that stress levels among students is 0.8 higher in female students compared to male students. Also, there is a difference in means of the gender groups regarding the variable "Concentration" with a difference of 0.47 , showing that females felt less concentrated than males.

The differences in the means of groups (male and female) for the variables "Desire to study" and "Laziness" is very small, respectively 0.05 and 0.23 .

Using Independent T-test, was analyzed if there is significant difference between groups (male and female) for the variables: Stress, Desire to Study, Laziness and Concentration.

(Table 3: Independent T-Test for Variable "Stress")

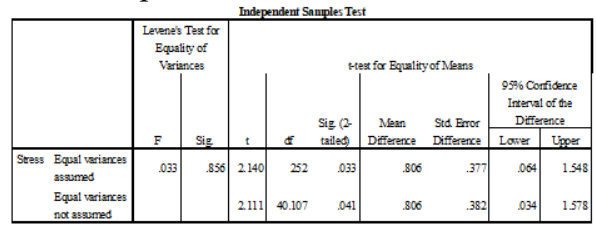

For the variable Stress: $p$ - value is 0.041 , more than 0.01 that means that there are no significant differences between genders for the variable Stress. 
(Table 4: Independent T-Test for Variable "Desire to

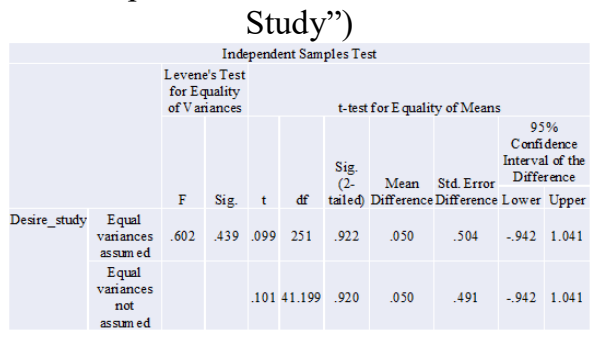

For the variable Desire to Study: $p$ - value is 0.920 , more than 0.01 that means that there are no significant differences between genders for the variable Desire to Study.

(Table 5: Independent T-Test for Variable "Laziness")

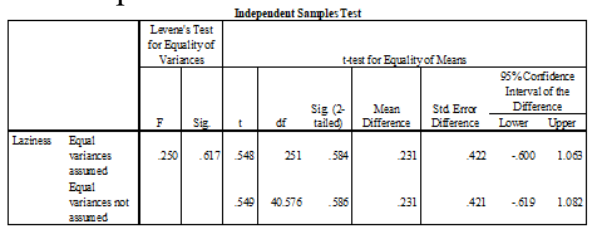

For the variable Laziness: $p$ - value is 0.586 , more than 0.01 that means that there are no significant differences between genders for the variable Laziness.

(Table 6: Independent T-Test for Variable "Desire to Study")

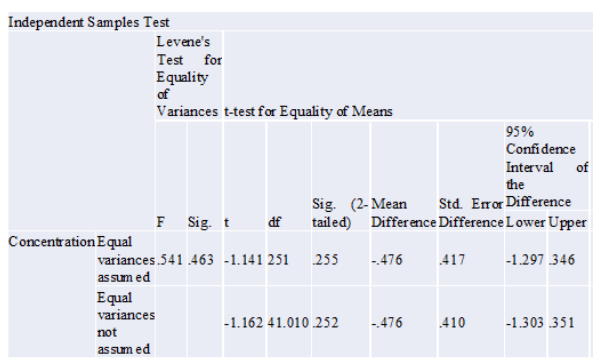

For the variable Concentration: $\mathrm{p}$ - value is 0.252 , more than 0.01 that means that there are no significant differences between genders for the variable Laziness.

The independent sample t-test indicates that there are no significant group differences for all variables in this study (Stress, Desire to Study, Laziness and Concentration) suggesting that the male and female levels of experiencing each variable are not affected by gender.

Pearson Coefficient for the correlation will help us to investigate on the relation between variables.

Pearson Coefficient shows that there is a week negative correlation between variables Stress/Desire to Study, $(r=$ $-0.252)$.
(Table 7: Correlation between "Stress" and "Desire to Study")

\begin{tabular}{|c|c|c|c|}
\hline & & Stress & Desire study \\
\hline Stress & $\begin{array}{l}\text { Pear son Correlation } \\
\text { Sig. (2-tailed) } \\
\text { N }\end{array}$ & $\begin{array}{l}1 \\
254 \\
\end{array}$ & \begin{tabular}{|l}
$-.252^{* 4}$ \\
.000 \\
253 \\
\end{tabular} \\
\hline Desire_study & $\begin{array}{l}\text { Pear son Correlation } \\
\text { Sig. (2-tailed) } \\
\text { N }\end{array}$ & $\begin{array}{l}-.252^{\circ-} \\
.000 \\
253\end{array}$ & $\begin{array}{l}1 \\
253\end{array}$ \\
\hline
\end{tabular}

Pearson Coefficient shows that there is a week positive correlation between variables Stress/Laziness, $(r=0.265)$.

(Table 8: Correlation between "Stress" and "Laziness")

\begin{tabular}{|c|c|c|c|}
\hline \multicolumn{4}{|c|}{ Correlations } \\
\hline & & Stress & Lazyness \\
\hline \multirow[t]{3}{*}{ Stress } & Pearson Correlation & 1 & $.265^{4 *}$ \\
\hline & Sig. (2-tailed) & & .000 \\
\hline & $\mathrm{N}$ & 254 & 253 \\
\hline \multirow[t]{3}{*}{ Laziness } & Pearson Correlation & $.265^{* *}$ & 1 \\
\hline & Sig. (2-tailed) & .000 & \\
\hline & $\mathrm{N}$ & 253 & 253 \\
\hline
\end{tabular}

Pearson Coefficient shows that there is a week negative correlation between variables Stress/Concentration to Study, $(r=-0.343)$.

(Table 9: Correlation between "Stress" and "Concentration")

\begin{tabular}{|c|c|c|c|}
\hline & & Concentration & Stress \\
\hline Concentration & $\begin{array}{l}\text { Pear son Correlation } \\
\text { Sig. (2-tailed) } \\
\text { N }\end{array}$ & $\begin{array}{l}1 \\
253\end{array}$ & $\begin{array}{l}-.343^{* 4} \\
.000 \\
253\end{array}$ \\
\hline Stress & $\begin{array}{l}\text { Pear son Correlation } \\
\text { Sig. (2-tailed) } \\
\text { N }\end{array}$ & $\begin{array}{l}-.343^{* *} \\
.000 \\
253\end{array}$ & $\begin{array}{l}1 \\
254\end{array}$ \\
\hline
\end{tabular}

Pearson Coefficient shows that there is a negative correlation between variables Laziness/Desire to Study, ( $\mathrm{r}$ $=-0.471$ ).

(Table 10: Correlation between "Laziness" and "Desire to Study")

\begin{tabular}{|c|c|c|c|}
\hline & & Lazyness & Desire_study \\
\hline Laziness & $\begin{array}{l}\text { Pear son Correlation } \\
\text { Sig. (2-tailed) } \\
\mathrm{N}\end{array}$ & $\begin{array}{l}1 \\
253 \\
\end{array}$ & $\begin{array}{l}-.471^{*} \\
.000 \\
252\end{array}$ \\
\hline Desire_study & $\begin{array}{l}\text { Pearson Correlation } \\
\text { Sig. (2-tailed) } \\
\mathrm{N}\end{array}$ & $\begin{array}{l}-.471^{+*} \\
.000 \\
252\end{array}$ & 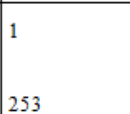 \\
\hline
\end{tabular}

Pearson Coefficient shows that there is a significant positive correlation between variables Desire to Study/Concentration, $(r=0.622)$.

(Table 11: Correlation between "Concentration" and "Desire to Study") 


\begin{tabular}{|c|c|c|c|}
\hline & & $\begin{array}{l}\text { Desire_stud } \\
\text { y }\end{array}$ & $\begin{array}{l}\text { Concentratio } \\
\text { n }\end{array}$ \\
\hline Desire_study & $\begin{array}{l}\text { Pearson } \\
\text { Correlation } \\
\text { Sig. (2-tailed) } \\
\mathrm{N}\end{array}$ & $\begin{array}{l}1 \\
253 \\
\end{array}$ & $\begin{array}{l}.622^{* *} \\
.000 \\
252 \\
\end{array}$ \\
\hline $\begin{array}{l}\text { Concentratio } \\
\mathrm{n}\end{array}$ & $\begin{array}{l}\text { Pear son } \\
\text { Correlation } \\
\text { Sig. (2-tailed) } \\
\mathrm{N} \\
\end{array}$ & $\begin{array}{l}.622^{* *} \\
.000 \\
252 \\
\end{array}$ & 1 \\
\hline
\end{tabular}

$\mathrm{R}$-Squared is a statistical measure of fit that indicates how much variation of a dependent variable is explained by the independent variable(s) in a regression model. In this research, R-Squared for a combination of variables is as below:

(Table 12: Linear Regression of "Stress" and "Desire to Study")

\begin{tabular}{|c|c|c|c|c|}
\hline Model & $\mathrm{R}$ & R Square & $\begin{array}{ll}\begin{array}{l}\text { Adjusted } \\
\text { Square }\end{array} & \mathrm{R} \\
\end{array}$ & $\begin{array}{l}\text { Std. Error of the } \\
\text { Estimate }\end{array}$ \\
\hline 1 & $.252^{\mathrm{a}}$ & .063 & .060 & 2.577 \\
\hline
\end{tabular}

R Square of .063 shows that only $6.3 \%$ of the desire to study of respondents is explained by stress. (Table 12)

(Table 13: Linear Regression of "Stress" and "Concentration")

\begin{tabular}{|c|c|c|c|c|}
\hline \\
\hline Model & $\mathrm{R}$ & R Square & $\begin{array}{ll}\begin{array}{l}\text { Adjusted } \\
\text { Square }\end{array} & R \\
\end{array}$ & $\begin{array}{l}\text { Std. Error of the } \\
\text { Estimate }\end{array}$ \\
\hline 1 & $.343^{\mathrm{a}}$ & .118 & .114 & 2.077 \\
\hline
\end{tabular}

$\mathrm{R}$ Square of .118 shows that only $11.8 \%$ of the concentration during work or study of respondents is explained by stress. (Table 13)

(Table 14: Linear Regression of "Desire to study" and "Concentration")

\begin{tabular}{|c|c|c|c|c|}
\hline Model & $\mathrm{R}$ & R Square & $\begin{array}{ll}\begin{array}{l}\text { Adjusted } \\
\text { Square }\end{array} & R \\
\end{array}$ & $\begin{array}{l}\text { Std. Error of the } \\
\text { Estimate }\end{array}$ \\
\hline 1 & $.622^{\mathrm{3}}$ & .387 & .384 & 1.735 \\
\hline
\end{tabular}

R Square of 0.387 shows that $38.7 \%$ of the concentration of respondents is affected by desire to study. (Table 14)

(Table 15: Linear Regression of "Stress" and "Laziness")

Model Sum mary
\begin{tabular}{|l|l|l|l|l|}
\hline Model & $R$ & R Square & $\begin{array}{l}\text { Adjusted } \\
\text { Square }\end{array}$ & $\begin{array}{l}\text { R } \\
\text { Etd. Error of the } \\
\text { Estimate }\end{array}$ \\
\hline 1 & $.265^{\mathrm{a}}$ & .070 & .066 & 2.154 \\
\hline
\end{tabular}
a. Predictors: (Constant), Stress

R Square of 0.070 indicates that only $7 \%$ of laziness of respondents is explained by stress. (Table 15)

(Table 16: Linear Regression of "Desire to study" and "Laziness")

\begin{tabular}{|c|c|c|c|c|}
\hline \multicolumn{5}{|r|}{\begin{tabular}{l|l}
$R$ & Std. Error of the
\end{tabular}} \\
\hline Model & $\mathrm{R}$ & R Square & Square & Estimate \\
\hline 1 & $.471^{\mathrm{3}}$ & .222 & .219 & 2.346 \\
\hline
\end{tabular}

R Square of 0.222 indicates that $22.2 \%$ of desire to study of respondents is explained by laziness. (Table 16)

\section{DISCUSSION}

Descriptive Statistics: In the data reported in this research is noted that the female students have higher stress levels and lower concentration levels. Stress level of students during 2020 in a scale from 1 to 10 ( 1 is not at all, 10 extremely much), is on average 7.77 in female students and 6.97 in male students and Concentration level of students during 2020 is on average 4.81 in female students and 5.28 in male students. Other researches referred in this paper at the introduction session, indicates that stress levels and mental health has been at higher levels in female students rather than male students, indicating signals of potential decreases in their academic performance. [2]

Gender Differences: The independent sample t-test indicates that there are no significant group differences for all variables in this study (Stress, Desire to Study, Laziness and Concentration) suggesting that the male and female levels of experiencing each variable are not affected by gender.

This conclusion may be limited to the sample structure that is $87.4 \%$ female and $12.6 \%$ male, and the small number of male students participating in the study. (32 male students among 221 students who reported their gender in the survey).

Correlations between variables and $R$ Square analysis: Negative correlation is a relationship between two variables in which one variable increases as the other decreases, and vice versa. Positive correlation is a relationship between two variables in which both variables in the same direction.

In this research, variables that have negative correlation, are:

- Pearson Coefficient shows that there is a week negative correlation between variables Stress/Desire to Study, $(r=$ $-0.252)$.

- Pearson Coefficient shows that there is a week negative correlation between variables Stress/Concentration, $(r=$ $0.343)$.

- Pearson Coefficient shows that there is a negative correlation between variables Laziness/Desire to Study, (r $=-0.471$ ).

The most negative correlation between variables compared to other combinations in this study, is between variables Laziness and Desire to Study. The higher Laziness levels are, the lower is the Desire to Study. 
In this research, variables that have positive correlation, are:

- Pearson Coefficient shows that there is a week positive correlation between variables Stress/Laziness, $(r=0.265)$.

- Pearson Coefficient shows that there is a significant positive correlation between variables Desire to Study/Concentration, $(r=0.622)$.

The most positive correlation between variables compared to other combinations in this study, is between variables Desire to Study and Concentration. The higher Desire to Study Levels are, the higher are the Concentration Levels. Knowing that concentration is very important to students' academic performance, it is a challenge it times of pandemic to find ways to boost students desire to study.

$\mathrm{R}$ Squared analysis supports what is discussed above. $\mathrm{R}$ Square of 0.387 shows that $38.7 \%$ of the concentration of respondents is explained by desire to study.

$\mathrm{R}$ Square of .118 shows that only $11.8 \%$ of the concentration during work or study of respondents is explained by stress.

Referred to the data in this study, concentration during work or study is affected in a large level from the desire to study, $38.7 \%$, while the desire to study itself is affected just $11.8 \%$ from stress. This indicates that there are other factors that affect the desire to study among students which need to be seriously consider. Improving other factors rather than stress that affect desire to study will improve students' concentration.

Further research is needed for this.

$\mathrm{R}$ Square of 0.070 indicates that only $7 \%$ of laziness of respondents is explained by stress. So, stress levels explain at a very low rate why students are feeling lazy during the pandemic of 2020. Others factors may affect this and there is a need for further studies. A proposition may be that isolation and the lack of mobility increases laziness among people, so physical activity can improve the variables. It is important to investigate on laziness as R Square of 0.222 indicates that $22.2 \%$ of desire to study of respondents is explained by laziness. As highlighted in this discussion session, desire to study plays an important role in concentration.

\section{CONCLUSIONS}

Statistical data of this research show that:

Stress level of students during 2020 in a scale from 1 to 10 ( 1 is not at all, 10 extremely much), is on average 7.77 in female students and 6.97 in male students. The desire to study of students during 2020 in a scale from 1 to 10 (1 is not at all, 10 extremely much), is on average 5.71 in female students and 5.66 in male students.
Laziness level of students during 2020 in a scale from 1 to 10 ( 1 is not at all, 10 extremely much), is on average 7.61 in female students and 7.38 in male students.

Concentration levels of students during 2020 in a scale from 1 to 10 ( 1 is not at all, 10 extremely much), is on average 4.81 in female students and 5.28 in male students.

Pearson Coefficient shows that there is a week negative correlation between variables Stress/Desire to Study, ( $\mathrm{r}=$ -0.252).

Pearson Coefficient shows that there is a week positive correlation between variables Stress/Laziness, $(r=0.265)$.

Pearson Coefficient shows that there is a week negative correlation between variables Stress/Concentration to Study, $(r=-0.343)$.

Pearson Coefficient shows that there is a negative correlation between variables Laziness/Desire to Study, ( $\mathrm{r}$ $=-0.471$ ).

Pearson Coefficient shows that there is a significant positive correlation between variables Desire to Study/Concentration, $(\mathrm{r}=0.622)$.

$\mathrm{R}$ Square of .063 shows that only $6.3 \%$ of the desire to study of respondents is explained by stress.

$\mathrm{R}$ Square of .118 shows that only $11.8 \%$ of the concentration during work or study of respondents is explained by stress.

R Square of 0.387 shows that $38.7 \%$ of the concentration of respondents is explained by desire to study.

R Square of 0.070 indicates that only $7 \%$ of laziness of respondents is explained by stress.

In conclusion, this research suggests:

The most positive correlation between variables compared to other combinations in this study, is between variables Desire to Study and Concentration. The higher Desire to Study Levels are, the higher are the Concentration Levels. Knowing that concentration is very important to students' academic performance, it is a challenge it times of pandemic to find ways to boost students desire to study.

Referred to the data in this study, concentration during work or study is affected in a large level from the desire to study, $38.7 \%$, while the desire to study itself is affected just $11.8 \%$ from stress. This indicates that there are other factors that affect the desire to study among students which need to be seriously consider. Improving other factors rather than stress that affect desire to study will improve students' concentration.

Further research is needed for this.

$\mathrm{R}$ Square of 0.070 indicates that only $7 \%$ of laziness of respondents is explained by stress. So, stress levels explain at a very low rate why students are feeling lazy during the pandemic of 2020. Others factors may affect this and there is a need for further studies. A proposition may be that isolation and the lack of mobility increases 
laziness among people, so physical activity can improve the variables.

\section{REFERENCES}

[1] World Bank, (2021), Urgent, Effective Action Required to Quell the Impact of Covid-19 on Education Worldwide,

https://www.worldbank.org/en/news/immersivestory/2021/01/22/urgent-effective-action-required-toquell-the-impact-of-covid-19-on-education-worldwide

[2] Burt Ch., (2021), "95\% of students feel mental health strains of pandemic". Retrieved at: https://universitybusiness.com/95-of-students-feelmental-health-strains-ofpandemic/\#: :text=A\%20new\%20study\%20shows\%20th e,students $\% 2 \mathrm{C} \% 20$ including $\% 20$ negative $\% 20$ academic $\%$ 20outcomes.\&text=Colleges $\% 20$ and $\% 20$ universities $\% 20$ have $\% 20$ prioritized,throughout $\% 20$ the $\% 20$ COVID $\% 2 \mathrm{D} 1$ 9\%20pandemic.

[3] ACHA, (2019), "Canadian reference group. Executive summary 2019". Retrieved at: https://www.cacuss.ca/files/Research/NCHAII\%20SPRING\%202019\%20CANADIAN\%20REFEREN CE\%20GROUP\%20EXECUTIVE\%20SUMMARY.pdf

[4] Hellemans K., Abizaid A., Gabrys R., McQuaid R., Patterson Z., (2020), "For university students, COVID-19 stress creates perfect conditions for mental health crises". Retrieved at: https://theconversation.com/for-university-students-covid19-stress-creates-perfect-conditions-for-mental-healthcrises-149127

[5] Bozdo R., (2021), "The impact of anxiety on perceptions during lockdown of COVID-19". Retrieved at:

https://www.wseas.org/multimedia/journals/economics/20 21/b025107-1253.pdf

[6] Petretto D., Msala I., Msala C., "School closure in the outbreak of Covid-19", (2020). Retrieved at: https://clinical-practice-and-epidemiology-in-mentalhealth.com/VOLUME/16/PAGE/189/

[7] Mirahmadizadeh A., Ranjbar K., Shahriarirad R., Erfani A., Ghaem H., Jafari K., Rahimi T., "Evaluation of students' attitude and emotions towards the sudden closure of schools during the COVID-19 pandemic: a cross sectional study". Retrieved at: https://bmcpsychology.biomedcentral.com/articles/10.118 6/s40359-020-00500-7

[8] Basheti I., Mhaidat Q., Mhaidat H., (2021), "Prevalence of anxiety and depression during COVID-19 pandemic among healthcare students in Jordan and its effect on their learning process: A national survey". Retrieved at: https://journals.plos.org/plosone/article?id=10.1371/journ al.pone. 0249716

\section{Creative Commons Attribution License 4.0 (Attribution 4.0 International, CC BY 4.0)}

This article is published under the terms of the Creative Commons Attribution License 4.0

https://creativecommons.org/licenses/by/4.0/deed.en_US 